\title{
LETTERS-CONCISE RESEARCH REPORTS \\ Letter About: Use of Mortality as an Endpoint in Noninferiority Trials May Lead to Ethically Problematic Conclusions
}

Walter Palmas, MD, MS, FAHA

Columbia University Medical Center, New York, NY, USA.

J Gen Intern Med 35(6): 1890

DOI: $10.1007 /$ s11606-019-05049-9

(C) Society of General Internal Medicine 2019

$\mathrm{D}$

ear Sir/Madam,

I read with great interest the outstanding work by Andrew M. Hersh and colleagues. Their study illustrates very clearly the ethical dangers of using mortality as an endpoint in noninferiority trials. ${ }^{1}$

Their results remind us that some participants in these studies, when randomized to the new treatment, may have died because they did not receive the "alternative treatment," which already had proven value. One of the ethical principles outlined by the Belmont Report, the principle of Beneficence, is probably violated in those situations. $^{2}$

Another essential principle, Respect for Autonomy, is probably violated as well. It seems unlikely that lay people understand the nuances of noninferiority design. In fact, many participants in noninferiority trials are not given adequate information and may erroneously believe that they are enrolling in a superiority clinical trial. ${ }^{3}$
A balance between prospective benefits versus the accepted loss in efficacy that one considers "noninferior" requires thoughtful consideration in noninferiority trials. Is it hard to imagine how our metaphorical ethical scale will ever be balanced when the heavy weight of participants' deaths lies on one end of it.

Corresponding Author: Walter Palmas, MD, MS, FAHA; Columbia University Medical Center, New York, NY, USA (e-mail: wp56@cumc. columbia.edu).

Compliance with Ethical Standards:

Conflict of Interest: The author declares that he does not have a conflict of interest.

\section{REFERENCES}

1. Hersh AM, Walter RJ, Abberegg SK. Use of Mortality as an Endpoint in Noninferiority Trials May Lead to Ethically Problematic Conclusions. J Gen Intern Med 2019;34:618-623.

2. Palmas W. Who protects participants in non-inferiority trials when the outcome is death? Res Ethics;0:1747016118764304.

3. Doshi P, Hur P, Jones M, Albarmawi H, Jefferson T, Morgan DJ, Spears PA, Powers JH, 3rd. Informed Consent to Study Purpose in Randomized Clinical Trials of Antibiotics, 1991 Through 2011. JAMA Intern Med 2017;177:1452-1459.

Publisher's Note Springer Nature remains neutral with regard to jurisdictional claims in published maps and institutional affiliations. 